\title{
The Video-Essay the Tamed Centaur of Cyberspace: New Perspectives of Online Communication
}

\author{
Ligia SMARANDACHE, PhD \\ Cinema and Media Department \\ Faculty of Theatre and Film \\ Babeș-Bolyai University, Cluj-Napoca, Romania \\ E-mail: ligia.smarandache@ubbcluj.ro
}

\begin{abstract}
The title of the present paper refers to a well-known article by Phillip Lopate named metaphorically "In Search of the Centaur: The EssayFilm”, published in 1992. The syntagma 'tamed Centaur' contains a contradiction in terms. The twisted new sense proposed changes the very inner form of the essay from an untamed elusive creature to a domestic one. Being an expression of freedom, the video-essay is very hard to define and even harder to be fixed in conventions. Nevertheless, the new online videosharing environment empowers the "protean form" of the video-essay-as Lopate calls it- to have a unified voice and a proper place. If it paid the price of regularization, it could become more visible and even acknowledged as an effective means of communication. This article stresses the importance of using alternative ways of understanding that go beyond logocentrism and can better reflect the complexity of our communication. In this respect, the video-essay qualifies as the most appropriate form of audiovisual grammar, able to express emotions and abstract thinking in equal measure.
\end{abstract}

Keywords: Essay-film; Video-essay; Online communication; Audiovisual; Video-channel. 


\section{Introduction}

This paper approaches film semiotics and linguistics theories to show the importance of the video-essay as a cognitive tool in online communication. From the standpoint of film grammar, the video-essay qualifies as the closest thing to Jerry Fodor's Language of Thought Hypothesis. His theory posits that the language we speak is preceded by an internal language that is deeply rooted in our neural structure, which is the first intentional content carrier. The article aims to show that this prior thinking named mentalese is made up of representations that share characteristics with the video-essay: nonlinearity, metaphorical understanding, abstract communication. Known as an in-between genre with a shape-shifting feature, the video essay has been deemed elusive and heretical by the traditional media. The online environment allows video-essays to develop into various forms, adding new features. The Nowness channel case study bears out the conclusion that there is a new tendency in the video-essay manifestation that could gain popularity, namely regularization. In other words, the wild centaur has been tamed after gaining a certain structure and a little bit more uniformity. The visual aesthetics of Nowness channel, its videos grouped according to topics, the auto-reflexive voiceover that links non-linear images - are all constant elements that make the video-essay a more intelligible genre. With its interactive features, cyberspace empowers the video essay to become a universal language that can organize complexity. Its effectiveness lies in its intrinsic capabilities of combining intuition with rationality in building arguments. Like conceptual metaphors, the video-essay is a cognitive tool that allows us to name what can be named and shows what cannot be named.

\section{Languages as cognitive instruments}

Using Astruc's statement: "film language is the exact equivalent of literary language" (1948) as a starting point, we will draw a parallel between the theories of verbal communication and those of audiovisual communication. The comparison between film and textual discourse dominated the film criticism of the 1950s, especially in France. Language in its essence, as a form of understanding, knowledge and communication, influences the way we think and how we perceive reality.

The best example of language as a cognitive tool is the mathematical sign "0". Without zero it would be very difficult to make any calculations, even the most basic. This number affects the numerical values wherever it appears but has no value in itself. This symbol makes possible the existence of a certain kind of thinking that has led to the most powerful technology in the contemporary world. If we had used the Roman numerals we would not have reached the binary calculation system (Postman, 1992).

Another example, which demonstrates that spoken language is a kind of invisible technology, as Postman (1992) calls it, is metaphor. The study of metaphor 
placed in a broader field, that of philosophical and anthropological research, views metaphor as a distinctive feature of humanity and not just as a stylistic process of literary aesthetics. The double meaning of metaphor, like the double affiliation of the essay, comes from the very universal condition of the human being to be somewhere between the objective and the subjective world (Blaga, 1985). The metaphorical meaning of some words often comes from the conjunction of abstract terms with simpler terms, usually adjectives or verbs, which designate indicative actions or words from general human experience. In point of fact, it is the description of a relationship -human interaction with the environment- rather than an objective labeling of concepts (Lakoff, Johnson, 2003). The conceptual metaphor as the authors George Lakoff and Mark Johnson call it, helps to understand terms that are either too vague or too abstract. Behind expressions such as: "theoretical foundations", "theory with solid arguments", "its argument stands", is the metaphor: "theories are buildings". This demonstrates that metaphor is fundamentally related to our conceptual system, through which we think and act (Lakoff, Johnson, 2003, 47). All these conceptual metaphors are conventions that are part of the common language and we usually use them without a clear intention to metaphorize.

Unlike the conceptual metaphor, which is used to support the clarification of certain concepts, the creative metaphor often seeks to draw out a word from its category, to give it a broader meaning, or to describe an unusual experience (Lakoff, Johnson, 2003). Poetic and literary metaphors, which represent the particular and are used for artistic purposes, have been dealt with by many philosophers but only few of them consider its double condition. Among them the Transylvanian poet and philosopher Lucian Blaga reveals the very nature of humans as "metaphorizing animals" by underlying its double precarious condition of not having the means to express the physical world in which we live and not having the means to disclose the mysterious dimension in which we live (Blaga, 1985). Considering Blaga's statement as a point of departure, essays, whether on film or in literature deal with both dimensions, which places them on the cutting edge between objectivity and subjectivity. In order to be able to analyze the cognitive feature of film essays and make comparisons with literary essays, we have to start with what is called cognitive turn.

\subsection{Linguistic film theories}

"The fundamental problem of the cinema is how to express thought. The creation of this language has preoccupied all the theoreticians and writers in the history of the cinema, from Eisenstein down to the scriptwriters and adaptors of the sound cinema." (Astruc, 1948)

The categorization in the theory and philosophy of the film takes over the directions launched in the linguistic field. Russian formalists made the first analogy be- 
tween film and language, taking over the structuralist theories. Despite Saussure's influence, formalist aesthetics had two positive aspects: it was anti-grammatical, anti-normative, and it launched the concept of internal language (Buckland, 2004). Then, Metz's much debated theory raises the issue of establishing relationships between articulated natural language and filmic language. The aim of his research was to reach the basis of linguistic metaphor, looking for its resonance in the world of film. Jakobson, one of structuralists of the Linguistic Circle of Prague, isolates the poetic function from the narrative function of language (Stam, Burgoyne, Flitterman-Lewis, 1992). He also states that common language not only has the ability to designate objects, but also to describe reflexive operations (1992). However, Jean Mitry observed the error of theorists in considering a priori verbal language as the exclusive form of language, which makes them put the seal on the film language, which is different anyway, as being a non-language. He emphasizes the importance of cinema's using another type of language, different from the articulated one, which cannot be subsumed to the conventional structures of the spoken language. Jean Mitry tried to confront the terms of expression, language, or lingua in terms of film, but without resorting to the study of language itself. In Esthétique et Psychologie du Cinema Jean Mitry demonstrates that cinema is a means of expression that organizes, constructs, and communicates thoughts, and can be considered, quite frankly, a language. For him, language is a system of signs or symbols that allows for things to be designated through naming, and allows the meaning of ideas and the translation of thoughts.(Aumont, Bergala, Marie, 2007) Failure of reducing the language to a set of logical relationships between signs has been pointed out by Derrida's deconstructivism, followed by Foucault, Lacan, and later Barthes. Therefore, film semiotics is much easier to build around the theory of representation, known as the Language of Thought Hypothesis.

\subsection{The issue of representation, or, Language of Thought Hypothesis}

Although there are a number of variations on the theory of representation, Jerry Fodor's The Language of Thought, built on Noam Chomsky's linguistic theories is the most appropriate for describing video-essay. Chomsky (2006) argues that the faculty of spoken language is part of our biological dowry and is genetically determined. For him, the study of language involves an initial phase, which is universal grammar. The role of this pre-thinking is to make explicit a subsequent phase which is the natural language. For Chomsky, natural language is distinguished because it generates an infinite phenomenon from and through finite means (linguistic units - which have no meaning in themselves), recognizing the two levels of semiotic theory (Stam, Burgoyne, Flitterman-Lewis, 1992, 21).

Fodor (2008) continues this theory by asserting that we think in an internal language that he calls "mentalese". Mentalese is not the language we speak (e.g., 
French, German, etc.), but something before it. Our mental capacity is not something we learn, but it is an intrinsic capacity of our brain. Like other languages, "mentalese" is medium-independent. Thus, there are no written or spoken words in our mind; language exists in our neural structure. According to the Language of Thought Hypothesis, recalled by Cilliers (1998, 62), thinking is a symbolic system made by a certain organization in the human brain. For him, the Representational Theory of Mind is a confederation of theses placed in a canonical formula.

- The first thesis is related to causality and explains the relationship between the mental state under a certain intentionality (between desire and action).

- The second is about mental representations which are the first carriers of intentional content, for example the idea in its intuitive state. The metaphysical possibility of thinking without language, or of having mental representation without thought.

- The third refers to computational thinking.

- The fourth: meaning is information (more or less).

Fodor's theory could be easily translated into cinema language, specifically into film-poetry. These mentalese units could be seen as non-narrative images clustered together around a feeling or an abstract idea.

\subsection{The structures of film poetry}

Positioning the cinema-essay between its kindred genres, poetry and prose, we will bring into discussion a debate called Poetry and the Film, held in Cinema 16 in Oct. 1953, which analyses the language of cinema poems. In this symposium, Maya Deren (in Maas, 1963) gives us a clear picture of the poetic genre in film. In her opinion, the distinction between these two forms, the narrative and the poetic, is made from the construction. She compares this distinction with the form of the two axes, the vertical and the horizontal. Although both forms (poetry and prose) can look at the same event, the difference between them is in the angle from which that event is viewed. Deren (in Maas, 1963) compares the poetic construction, seen through a vertical investigation of the situation, in which the focus is on how that situation feels or what it means, with the horizontal construction of the drama, in the form of a chain of moments that develop from one to another. A poem creates visible or auditory forms of what is invisible, such as feeling, emotion, or the metaphysical context of the moment, while in drama the interest is rather to develop a situation from another situation. From the verticals' perspective of the relationship between images in dreams, poetry and editing are similar, because they are held together by an emotion or a meaning they have in common, rather than a logical action. In other words, here it is not an action that leads to another action (horizontal development), but they are gathered in a center (vertical axis), in that they all refer to a common emotion, otherwise, the incidents themselves would be disparate. While 
in so-called horizontal development logic the action itself, in vertical development, logic is a central emotion or idea that draws disparate images containing that common thread that I have mentioned (Maas, 1963).

Ken Kelman's (1963) views resemble Deren's, both being related to the poetic and the essayistic genre. For him, the lyrical poem is the expression of direct communication, of visions, sensibilities, or thoughts, regardless of the means of expression. The artist can use action, dialogue, image, sounds, or music to get the effect he wants, the way he does it is less important. Its primary purpose is to convey the idea. "Film-poem must be primarily developed in terms of personal, "abstract" expression; and only secondarily to that may narrative, or any other formal effect, be introduced. " (Kelman, 1963). Kelman's words only go to confirm the vision of that vertical axis identified by Maya Deren, which is the transmission of an idea, a thought, or a feeling. As long as they converge on the main axis, the means of expression by which this is achieved can be of any nature. This is why the boundary between poetic and essay film is so uncertain. Both forms use the same vertical construction, being differentiated only by the personal reflexive style that the essay mainly contains.

\section{Film \& Video-Essays as features of the Centaur}

In terms of film language, there is no distinction between film-essay and videoessay as long as they both use the same grammatical structures, namely, a construction of arguments in a non-narrative approach of the topic, with a strong authorial point of view. Due to its freeform character and having no legitimate territory, the video-essay was rightly compared to a wild and lawless mythological creature, half-man, half-horse. The Centaur, stands in the gray area between Apollonian and Dionysian, combining both the conscious and the unconscious thoughts. Experiencing a primary language, which resembles the mental representations (mentalese) prior to their conscious processing, the video-essay has the ability to convey complex information at the subconscious level. Although sometimes it has a more or less logical discourse, its message targets the subject from several perspectives. Therefore, the purpose of the present study is not to find a legitimate framework for video essays, but rather to make an analysis of its complex communication capabilities. The first form of what we call essay was the literary essay, much before the invention of cinema. Thus, the film-essay borrows the name of his older brother due to the fact that it shares the same features. Therefore, this intricately in-between, subjective-objective, rational-irrational genre is better defined as a literary genre even though it is half-literature, half-science. 


\subsection{Literary Essay}

In literature, we can find the essay both in literary criticism and in political manifestos or philosophical arguments, as they are typical of statements that do not follow a deductive path, are bold, personal and innovative. Although the positivist conceptions of modernity do not encourage such an unorthodox practice as the essayistic one, with the advantage of such an adaptable form, the essay manages to survive. According to Adorno, the essay seeks to unravel the mystery of human life, like science, sociology or psychology, by different means, but no less valid. Due to the irreversible separation that positivism makes between scientific knowledge and art, any impulse of expression, at least in terms of scientific purism, endangers the objectivity of the statements made. Dividing the fate of a hybrid form between knowledge and art, the attestation of the essay still provokes resistance, being seen as reminiscent of a certain intellectual freedom of the Enlightenment. Instead of being a scientific achievement or an artistic creation, the effort of the essay resembles a child's freedom in which chance and play are essential. It shows what is loved and what is hated instead of an intellectual eloquence put in an absolute ethical form. He starts where he wants and ends when there is nothing more to say.(Adorno et al., 2007, 152) Another important feature enunciated by Adorno is the revolt against that ancient injustice over the transitory, a doctrine deeply rooted since the time of Plato, by which change and the ephemeral are not important to philosophy. "But the desire of the essay is not to seek and filter the eternal out of the transitory; it wants, rather, to make the transitory eternal"(Adorno et al., 2007, 159).

The essay does not tend towards a deductive or inductive construction. It suspends the traditional concept of method and uses the anti-systemic impulse as its procedure and introduces the concepts as it receives them, gaining precision from the relations between concepts. In fact, the usual objection brought to the essay is discontinuity and fragmentation. Following this radiograph, made with the intention of deciphering the meaning and purpose of the literary essay, from which are extracted only some of the ideas stated by Adorno, we dwell on the conclusion drawn by the author at the end of his article: "... the law of the innermost form of the essay is heresy"(Adorno et al., 2007, 171). Adorno's conclusion leaves open the delineation of the essay as a genre. Heresy has no rules, and although its existence is not denied, it cannot be clearly framed either. The essay is somewhere on the edge of the experiment, as an alliance between various artistic genres, its signature being personal reflection.

\subsection{The Film \& Video Essay: the elusive creature}

Due to its elusive nature and shape-shifting character, the video-essay has gone largely unnoticed in film criticism, with a few exceptions coming from its partisans in Avant-garde film or the French New Wave Cinema. Essayistic forms in cinema and online video platforms have flourished over the past decade, which led to an in- 
creased interest in theorizing them. New voices in film criticism now approach this undefinable film language through various lenses, as they are trying to determine the deep nature of the video-essay by describing its particularities. The distinction between film essay and video-essay bears no relevance, since both forms use the same principles of audiovisual language.

Although the term essay is quite common, especially in literature, the attempt to define it is like trying to hold water in the cup of your hands. It simply cannot be done. It pours through your fingers, and in the end, you're left with almost nothing. Given its uncertain, vague or changing status, the intention of this research is not to define it in such a way as to destroy its very character, drawing its limits, but rather to take a look at its intelligible, integrated forms. Having too many affiliations, the video essay often falls outside the predetermined categories, so the historical evolution of this type of language is difficult to follow. Its elusive character is often emphasized by its critics. Philip Lopate, for example, states that "It is easier to list the essay's practitioners than to fix a definition of this protean form"(Lopate, 1992). Jean-Pierre Gorin (2007), being himself a film essayist, compares the video essay to "termite art" re-evaluating a concept used before by Many Farber which designates a genre of films made without a budget, out of the pure adventure of knowledge.

"The strange thing is that the essay film flirts with genres (documentary, pamphlet, fiction, diary ... you name them) but never attaches itself to one. It flirts with a range of aesthetics but attaches itself to none. It is, in both form and content, unruliness itself, "termite art" and not "white elephant art" (Gorin 2007)

The common destiny of all essay expressions is that of a genre somewhere between other genres, and this middle state is their essence. Ursula Biemann (2003, 8) states:" For a documentary, they are seen as too experimental, self- reflexive and subjective, and for an art video they stand out for being socially involved or explicitly political". The territory of the film-essay spans non-narrative and non-commercial films, such as avant-garde or experimental. Yet, the simple fact that behind every artistic gesture lays a point of view or a personal idea makes the definition of the essay to overlap, in part, the experiment. Nor can the non-narrative character be a form of distinction, as long as the opposition to the classical narrative dominates all manifestations of video art. In fact, the essay is seen somewhere on the border between documentary and experimental film. It is nowhere and everywhere at the same time.

\subsection{Perspectives on the Film \&Video Essays}

\section{A construction of arguments}

The first conceptualization of the essay comes from a representative of avantgarde film, Hans Richter in the article "Der Filmessay: Eine neue Dokumentarfilms" (Film Essay: A New Form of Documentary Film). By allowing imaginative and artis- 
tic interventions, the film essay breaks the patterns of documentary film practice. It proposes a kind of film that empowers the author to make visible the invisible world of thoughts and ideas. Unlike the usual documentary film, which presents facts and information, the documentary essay presents complex reflections and thoughts that are not necessarily related to reality (Alter, 2003).

An important milestone for essays in fiction as theory and practice is the emergence of auteur cinema. As early as 1948, Alexandre Astruc published the manifesto "Naissance d'une nouvelle avant-garde: Le caméra-stylo" in which the film-essay as language is on the same pedestal as written research language. The notion of "caméra-stylo" that he introduces is, in fact, the association of the camera with the writing tool as an artistic form of expression, similar to literature or science. Thus, a kind of film is obtained on a non-narrative structure, in which the images are linked together by an abstract logic of thoughts, rather than by the topochronological conventions of the story. Astruc would like cinema to reach the intellectual and philosophical level that the written essay proposes. András Bálint Kovács appreciates the efficiency of the non-narrative formula of the essay in bringing arguments to support the themes it addresses, considering it in this sense superior to the narrative construction. Different scenes and events in the film are providing an opportunity for the characters to make their points of view, rather than specific actions. Thus, rather than the chronology, it is the conceptual logic of the arguments that rule the construction of the film (Kovács, 2007, 117).

\section{Organizing the complexity}

Ursula Biemann takes the essay out of the film matrix, placing it in a broader cultural and technological context, that of the digital image, the Internet and the development of new media. She sees essayistic work not as an attempt to document reality, but as a process of organizing complexity, a valuable ability as long as the video reflects not only the ever-changing audiovisual environment but also an increasing social complexity. The video-essay captures the most abstract and intangible processes of social and cultural transitions (Biemann, 2003).

\section{Cyberspace, a gallery of termites}

Cyberspace foreshadows the need to expand the audiovisual language in favor of expressing the complexity of the contemporary world. The human intrinsic need to assign meaning has to do with narrative knowledge. As long as the audiovisual tends to dominate the communication systems and social relations are based mainly on media platforms, the exchanges of narrative knowledge, seem to be essential in Lyotard's view. In this case, the narrative is not confined to storytelling like literature, but is closer to the expression of personal thoughts or opinions. If we try to understand micro-narratives, as envisaged by Lyotard, we can rely on Paul 
Chilliers's simple explanation: different groups (institutions, disciplines, communities) tell different stories about what they know and what they do. Their knowledge does not encompass a structured and complete logical whole, but rather takes the form of narratives. These are tools that allow them to achieve their goal and make sense of the things they do. As long as these narratives are local, they cannot take the form of one that unifies them all and encompasses great knowledge. The postmodern condition is characterized by the coexistence of a discourse of heterogeneous multiplicity, a state of things evaluated differently by different parties (Cilliers, $1998,114)$. If we see society in terms of a network, any given narrative forms a path or a trajectory in the network. The video-essay is a means to create micronarratives in postmodern times, which, having a clear path and multiple links in the complex and dynamic network of our society draw ever new narrative paths, mirroring a fragmented and impermanent world.

Less than half a century passed between Astruc's idea, at that time utopian, and the creation of media platforms and video libraries. The magnetic tape-recording system appeared in the 1970s. However, the biggest step was the transition from analog to digital (1995), which facilitated the production of audiovisual materials. The three situations enunciated by Astruc materialized in three steps that produced a paradigm shift in communication. Proving that the notion of "camera pen" is less utopian nowadays and is more like a future form of knowledge, Bjørn Sørenssen (2008) recontextualizes the following three aspects of Astruc's essay, applicable to the contemporary media situation:

- Providing new means of expression. (The film medium, for example, starts from an exclusive form and soon becomes a publicly available medium).

- Democratic use of this environment (media networks allow anyone to express themselves through video).

- Opens the possibility of different contemporary forms of use (Sørenssen, 2008, 49).

This eclectic Agora of user-generated video content brings together videographers, filmmakers, as well as amateur vloggers or video-geeks empowering them to express themselves regardless of format (length or specific structure). The videosharing technology, foreshadowed by many avant-garde artists, is a self-regulating system developed by its actors that allows for multiple forms of using audiovisual grammar. At a first glance, this videosphere, borrowing the term from Gene Youngblood (1970), seem to be a creation of termite art, that outlines its specific forms according to the socio-cultural needs and the technology used. That kind of termite art associated with the video-essay will best suit the needs and conditions of postmodern society. 


\subsection{NOWNESS a successful video platform for the tamed Centaur}

Having the chance to become a popular form of expression, the video essay faces the paradoxical situation of "being tamed" or of turning from heresy to more conventional aesthetics forms. In history, the film-essay is seen as a practice of avant-garde, whereas in contemporary online communication, it is often used by video geeks with or without filmmaking expertise. Auto-reflexive forms of filmmaking become a usual practice spread on vlogging channels that are less focused on content and more centred on the mood. The intuitive use of the essay as conveying and understanding information is often present in this mixed landscape of online video communication, but one remarkable example makes the difference between an unconscious use of the essay, practiced by average content creators, and the cleverly metaphorical use of the essay promoted by the video channel Nowness. Curator Jefferson Hack launched the channel in 2010, targeting professional filmmakers by doing an art and design video series. A carefully curated program promoting excellence, Nowness portrays the contemporary culture through short films, "celebrating the extraordinary of every day", as they put it (https://www.nowness. com/about). Throughout a decade of existence, Nowness has won eight prizes in the creative industries field, including three Webby and two Lovie awards, deemed the Oscars of the internet and digital media fields. Through the essay format, Nowness approaches various topics such as documentaries, dance and music videos, architecture and experimental fiction, all of them coming under the umbrella of culture and the humanities. In the beginning, Nowness was perceived as a fashion blog, promoting brands through different narratives. Lately, the channel has focused on special programs such as screenings and discussions on contemporary socio-cultural issues targeting globalization, equality, sustainability, the queer culture, or war and conflict zones, all of which are unsolved problems facing our society.

There is not a single mention of the notion of video-essay linked by the Nowness channel, yet, some of the essay features have been mentioned by its managing director, Daniel Coutinho. He talks about screening films one can identify as a "Nowness film", films that "you cannot see anywhere else" He also talks about their strong sense of authorship, in which "The filmmaker is bringing his point of view to the table and each individual has a different way of telling a story" (Angileri, n.d.). Even though Nowness commissioners do not claim the institutionalization of video-essay, the brand features of almost all videos overlap the attributes of the essay, such as the ones mentioned below.

Metaphorical understanding is one of the key elements that make the audience watch, more engaged in the story, as well as acquire more tools for understanding. Certain topics could hardly be understood from an objective perspective through mere numbers or facts. For example, tolerance can be cultivated only by stepping into someone else's shoes Therefore, in this case "\#Capturing Conflict" unveils the 
voices of artists who, through their work, have created visual metaphors of war and violence, or "\#Radically Queer" which documents stories of transgender people or other communities that are marginalized just for being different. Most of the videos are in fact portraits of people, regardless of the topic. Through these stories, the viewer is introduced in to the theme, whether it is fashion, architecture or a documentary. In the series called "In Residence", spaces are depicted through the lens of the people who live there, as they describe the way they perceive the light, the air, the objects, the furniture, even the walls. The feeling of being in that space describes the way they love the place they live in, as a reflection of their personalities. None of the videos shown uses a classical storyline which develops in a temporal and spatial continuity. The objective point of view is often replaced by the character's subjective auto-reflexive voice over, associated with a non-linear cumulus of impressions, created by images and sounds. This visualization of the language of thoughts is distinctive of the video essay. The diversity of topics finds coherence through a series of rules of aesthetics that mirror the features of the film-essay, while maintaining its intrinsic freeform. Spotting the particular and the moment of transition, fragments of an unpredictable reality, gives the feeling of a "Now" snapshot of a complex and multi-layered society. The film grammar used by the channel paints comprehensive picture of our global society perceived through the synaesthesia of a universal language that combines logic and emotion in a consistent database of short video-essay documentaries. As a feature of the new media, the cause-and-effect linear narrative is replaced with an interactive narrative in which the user can navigate through various topics. The hyper-narrative (in analogy with hypertext), as Lev Manovich (2002) calls it, can be seen as the sum of multiple trajectories within a database. The two types of narrative compete with one another, each claiming the same territory: the human culture demanding an "exclusive right to make meaning out of the world" (Manovich, 2002, 199). In this respect, Man With a Movie Camera, one of the first Film-essays by Dziga Vertov, is considered by Manovich "the most important example of database imagination in modern media art” $(2002,9)$.

The syntagma tamed Centaur associated with Nowness is meant to acknowledge the new era of video-essay when the loss of elusiveness is bought about by an increase in its importance. In the future, it is possible that its shape-shifting character be transformed into a whole of multiple essay genres. In the case of Nowness, the unity of style comes from the specific poetry of images, the use of light, and the excellent quality of the image. The guild of video advertisement creators found their voice and a place by creating these three to fifteen minutes' long documentaries that reflect the socio-cultural complexity of our life. 


\section{Conclusion}

Non-linear, fragmented, without aiming at giving a global vision, wishing to capture the ephemeral, the video-essay represents the peculiar and is spread in a complex network that changes over time. In a culture where the power of visual synthesis becomes a necessity, it is the expression of postmodern forms of communication in the transition from the written word to predominantly oral expression. The idea of point of view initiated by the contemporary culture can be best represented visually through the essay. Anticipated by Astruc, since 1948, video confession has become a widespread communicative formula in the Web 2.0 culture, used both by amateurs and professionals. Canadian artist Tom Sherman claims that currently: „Video is the way people place themselves at events and describe what happened. In existential terms, video has become every person's POV (point of view). It is an instrument for framing existence and identity"(Sherman, 2008, 161).

Contrary to coherently articulated written language, the intention of the video essay is rather to work with the intuitive human function. To work with the intuitive function, the veil of language must first be set aside in order to reach the first carrier of intentional content, which is Language of Thought, as Wittgenstein argues (qtd in Barnett, 2008). The mediating force of language is, in fact, only a filter that translates and structures that intentionality. If we combine Wittgenstein's statement, which is supported by other philosophers-see Chomsky's and Fodor's theories of language-, then the conclusion is that the essay as audiovisual language is intuitive and synthetic, in a state prior to its conscious processing. Unlike verbal language, which is analytical and rational, the intuitive one has the ability to convey complex information at the subconscious level. By moving beyond logocentrism, which relies on verbal argumentation, Laura Rascaroli calls the film-essay the thinking cinema that draws attention to its method of in between that capitalizes on the gap between sound and visual image or between image and voiceover. Thus, the viewer is invited to follow his/her reasoning and actively participate in the construction of meaning (Rascaroli, 2017). Manovich (2002) also asserts the fact that the digital media redefines the very identity of cinema, extending the audiovisual language far beyond the story-based narrative and drawing a parallel between avantgarde filmmakers and new media videographers.

The tight relationship between the features of the video-essay and the complex structure of contemporary society leads us to believe that the audiovisual form is best able to reflect a complex system. There are at least three important similarities between the notion of complexity outlined by Chilliers and the essay:

- Similarly to the nonlinear structure of the essay, a complex system must contain a large number of elements that interact dynamically with each other in a nonlinear way. 
- Complex systems are usually open systems. They interact with the environment, and as a result, it is quite difficult to establish the boundaries of a complex system.

- The essay captures transient processes. Complex systems have a history, they change over time, their past being co-responsible for present behavior. Complex systems are constantly evolving.

Placing the essay among the new video-graphic tendencies, Luka Arsenjuk describes it in pairs of opposite: "research and practice, analysis and creative synthesis, thought and materiality, form and feeling, concept and affect, abstractions of language and embodied sense perception" thus reuniting criticism and art (2016, 283). This complex communication, which combines the logos with a metaphorical visual content, conveys what cannot be articulated in words. The associative abstract language consisting of sounds and images reveal mental representations, the initial carriers of thought in its intentional form, the first messengers of universal communication. If we see language as a communication technology that helps to know and understand the world, an alternative to articulated or written language can only enrich knowledge and diversify communication within the system. Thus, the contemporary person will be able to choose the most efficient formula for what she/he wants to convey. For the purposes of conveying objective content, (which categorizes more or less formal elements) or scientific notions, the appropriate language will, of course, be the written one. The essence of human communication, on the other hand, is to express oneself with the help of the logos because, as Derrida argues, the need for communication springs from passion and feeling (Derrida, 2008).

With their eclectic content, digital media platforms, such as YouTube, raise important debates about the importance of popular culture and the significance of ordinary people's access to active and creative participation in culture. Professional and vernacular videos mix in a participatory culture, where digital media literacy is one of the fundamental requirements (Burgees, Green, 2018). In the last decade, YouTube has engaged in the media business, thus becoming more formalized and increasingly proactive in supporting creative production and developing original content (Burgees, Green, 2018, 17). In today's fragmented and discontinuous postmodernity, video-essay is an emerging cutting-edge language. Instead of being an in-between film genre, as Arsenjuk notices, "a sort of non-cinema, a non-place where the system of cinema loses its coordinates or a limit at which cinema turns upon itself," $(2016,275)$ the cyberspace reverses its negative characterization by promoting video-essay as a language of understanding. The Nowness channel is just one example of immersion in our postmodern global culture, which we perceive far beyond words, using our senses and feelings, understanding its complexity both at conscious and unconscious level. 


\section{References}

1. Adorno, T W, Hullot-kentor, B., \& Will, F. (2007). The Essay as Form. 32, 151-71. Retrieved January 19, 2021 from https://shifter-magazine.com/wp-content/uploads/2015/04/Ado rno-The-Essay-As-Form.pdf.

2. Alter, N. M. (2003). Memory Essays. In Ursula Biemann (ed.), STUFF IT: The Video Essay in The Digital Age, 14. Wien, New York: Institute for Theory of Art and Design.

3. Angileri, V. (n.d). Luxury Is Becoming an Intangible Experience. And Great Narratives Are a Way to Bring Those Experiences to Life. Folchstudio. Retrieved January 5, 2021 from https://www.folchstudio.com/insights/daniel-coutinho-nowness/.

4. Arsenjuk, L. (2016). 'To Speak, to Hold, to Live by the Image': Notes in the Margins of the New Videographic Tendency. In Elizabeth A. Papazian \& Caroline Eades (ed.) The Essay Film: Dialogue, Politics, Utopia. USA: Columbia University Press.

5. Astruc, A. (1948). The Birth of a New Avant-Garde: La Camera-Stylo. The New Wave, 17-23. Retrieved January 28, 2021 from http://artsites.ucsc.edu/faculty/gustafson/film $\% 20223$ /astruc.stylo.pdf

6. Aumont, J., Bergala, A., Marie, M., Vernet, M. (2007). Estetica Filmului [Aesthetics of Film]. Cluj: Idea.

7. Barnett, D. (2008). Movement as Meaning in Experimental Film. New York: Rodopi B.V. Amsterdam-NewYork.

8. Biemann, U. (2003). STUFF IT, The Video Essay in The Digital Age. Wien New York: Institute for Theory of Art and Design.

9. Blaga, L. (1985). Trilogia Culturii. Bucuresti: Editura Minerva.

10. Buckland, W. (2004). The Cognitive Semiotics of FilmTitle. Cambridge: Cambridge University Press.

11. Burgess, J., Green, J. (2018). YouTube Online Video and Participatory Culture. 2nd ed. Cambridge: Digital Media and Society Series.

12. Chomsky, N. (2006). Language and Mind. 3rd-rd ed. New York: Cambridge University Press.

13. Cilliers, P. (1998). Complexity and Postmodernism Understanding Complex Systems. London and New York: Routledge.

14. Derrida, J. (2008). Despre Gramatologie. 1967th ed. Cluj: Tact.

15. Fodor, J. A. (2008). LOT 2 The Language of Thought Revisited. New York: Oxford University Press.

16. Gorin, J.-P. (2007). Way of the Termite: The Essay in Cinema. Vienna International Film Festival. Retrieved January 11, 2021 from https://bampfa.org/program/way-termiteessay-cinema accessed.

17. Kelman, K. (1963). Film as Poetry. Film Culture, 29. Retrieved November 2, 2020 from https://ubu.com/papers/kelman_ken-film_poetry.html.

18. Kovács, A. B. (2007). Screening Modernism, European Art Cinema 1950-1980. Chicago, London: The University of Chicago Press.

19. Lakoff, G., Johnson, M. (2003). Metaphors We Live By. USA: The University of Chicago Press. 
20. Lopate, P. (1992). In Search of the Centaur: The Essay-Film. The Threepenny Review, 48(48), 19-22. Retrieved January 21, 2021 from http://www.essayfilmfestival.com/wpcontent/uploads/2015/03/Loparte.pdf.

21. Maas, W. (1963). Poetry and the Film: A Symposium. Film Culture, 29. Retrieved July 12, 2020 from http://www.ubu.com/papers/poetry_film_symposium.html .

22. Manovich, L. (2002). No The Language of New MediaTitle. Cambridge: MIT Press.

23. Postman, N. (1992). Technopoly_The_Surrender_of_Culture_to_Technology.Pdf. New York: Vintage Books Edition.

24. Rascaroli, L. (2017). NoHow the Essay Film Thinks Title. New York: Oxford University Press.

25. Sherman, T. (2008). Vernacular Video. In Sabine Niederer, Geert Lovink (ed.), Video Vortex Reader: Responses to YouTube. Amsterdam: Institute of Network Cultures.

26. Sorenssen, B. (2008). Digital Video and Alexandre Astruc's Caméra-Stylo: The New Avant-Garde in Documentary Realized? Studies in Documentary Film, 2(1). https://doi. org/10.1386/sdf.2.1.47.

27. Stam, R., Burgoyne, R., Flitterman-Lewis, S. (1992). New Vocabularies in Film Semiotics Structuralism, Post-Structuralism and Beyond. London: Routledge.

28. Youngblood, G. (1970). Expanded Cinema. New York: P. Dutton \& Co. 